She felt her voice control improved through singing and she was able to reduce night time panic about her breathing by using musical relaxation techniques. $\mathrm{L}$ will describe in her own words the subsequent far-reaching effects of the music therapy sessions.

DVD clips and audio recordings will provide evidence of her musical creativity - she had never composed music before but over a 6 month period was able to write a significant amount of choral music. The initial motivation was to leave a legacy for the family at her funeral - what resulted was a joyful service of thanksgiving with her family and friends in which everyone heard the beautiful music she had written.

Through her powerful and moving testimony in words and music she shows how someone living with a condition that often seems overwhelmingly hopeless can experience great joy and creativity and reclaim a sense of purpose and achievement.

\section{OP16 MOTOR NEURON DISEASE AND MUSIC THERAPY - A HOLISTIC APPROACH}

Helen Mackinnon St Michael's Hospice, Hereford, UK

10.1136/bmjspcare-2011-000100.16

This is a case study presentation of working through music therapy with a 66 year-old lady (L)who has been living with motor neuron disease (MND) for 5 years. At the start of the therapy sessions she had already reached the stage of tetra paresis and was increasingly concerned about her deteriorating speech and breathing and felt hopeless as well as helpless.

Searches reveal very little of the potential role of music therapy in MND - this presentation will open up the possibility of working through music in several different ways with people who live with this progressive life-limiting condition.

As a former healthcare professional with 20 years experience of working with people with MND, L is uniquely placed to comment on the benefits of music therapy on all aspects of her life - physiological, psychological, emotional, social and spiritual. 